\title{
Editorial
}

\section{ITET: Instructional Design Practices in Teacher Education}

\author{
Betül C. Czerkawski \\ Editor, ITET
}

\author{
Nicole Schmidt \\ Managing Editor, ITET
}

\begin{abstract}
Instructional design (ID) is the study of designing, developing, and assessing learning and teaching environments. With the advancement of online education, ID has once again become an important discipline for ensuring quality course offerings. At ITET, we do not believe that DBR, TPACK and instructional design are mutually exclusive concepts or that we should select one over another. The advancement of constructivist and, subsequently, connectivist paradigms influenced modern instructional design research significantly.
\end{abstract}

Keywords: instructional design; TPACK; DBR; constructivism; connectionism

Instructional design (ID) is the study of designing, developing, and assessing learning and teaching environments. What makes ID a distinct practice is its emphasis on 'effective' and efficient' instruction. Instructional designers have long argued that with the application of ID principles, teachers can utilize evidence-based techniques to guide classroom practices (Hoffman, 2013) and achieve better results with the student learning outcomes. From the instructional design perspective, one might expect that most teacher education programs would require ID as the foundational teacher knowledge, but in most cases, lesson planning tends to be the only ID practice being integrated into teacher education curricula.

With the advancement of online education, ID has once again become an important discipline for ensuring quality course offerings. Today, a significant number of teacher education programs offer blended or online courses to meet their students' needs while taking advantage of emerging educational technologies that enable networked learning experiences impossible a few years ago. Instructional designers provide many suggestions and contributions to those course offerings, but we are also witnessing a puzzling trend in teacher education; most teacher education research today uses design-based research (DBR) frameworks, which apply the learning sciences as their foundation, along with the teacher knowledge concept that derives from the TPACK framework. As Hoffman (2013) noted, since the early 2000s, we have not seen much 
research on the impact of ID on schools and teachers, which was previously the norm. To be fair, part of this shift is due to external government agency expectations in regard to the use of a design-based research framework in grant funding as well as the pressure teacher education programs are under to produce more evidence-based results.

The arguments about DBR and TPACK are not to deny their importance and usefulness in the toolset of teacher education researchers. Collins, Joseph, and Bielaczyc (2004) describe DBR as "experiments contextualized in educational settings, but with a focus on generalizing from those settings to guide the design process" (as cited in Dede, 2005, p.5). In other words, the idea is to complement existing experimental designs and add more accountability to educational research. Because DBR is about generalizability, size effects, and big sample sizes, NSF and similar agencies that fund large-scale teacher education research prefer to see it in most proposals they fund. TPACK is not a research method, but it gives a conceptual framework to teacher education research and aligns with DBR methodology nicely. While DBR and TPACK enhance our understanding of teachers' classroom performance, ID is focused on the direct enhancement of that performance rather than the observation of it.

At ITET, we do not believe that DBR, TPACK and instructional design are mutually exclusive concepts or that we should select one over another. We have to remember that both DBR and TPACK provide contextual understanding of teacher education programs when clinical experimental design methodologies were pushed upon educators to increase credibility and accountability of their research. However, we argue that turning away from instructional design practices when designing meaningful teacher education curricula has been costly. Today, most teacher education programs offer instructional design as an after-thought rather than an integrated part of their programs.

The advancement of constructivist and, subsequently, connectivist paradigms influenced modern instructional design research significantly. As a result, recent ID theories, models, and practices have produced more contextual and interpretive ideas, which may or may not align with the accountability and evidence-based trends in teacher education. However, instructional design, as a discipline, also offers interdisciplinary, authentic, and situated experiences that are much needed for realistic and pragmatic teacher preparation efforts. Teaching online is not an improvisational activity, and ID, with its systematic and carefully premeditated structure, provides the best outlet for accountability.

At ITET, we highly encourage our authors, who are in the business of teacher education, to push back on these accountability trends and offer more interdisciplinary and situated research studies on teacher education using instructional design, especially because instructional design and technology programs are mostly located within the colleges of education. The inclusion of more interdisciplinary studies will also alleviate some of today's issues surrounding diversity, or lack thereof, in teacher education programs by bringing multiple viewpoints and opinions from multiple disciplines (Ball \& Forzani, 2009). 


\section{References}

Ball, D. L., \& Forzani, F. M. (2009). The work of teaching and challenge for teacher education. Journal of Teacher Education. 60(5). 497-511.

Hoffman, E. S. (2013). Prospect of instructional design and teacher education. In: Spector J., Merrill M., Elen J., Bishop M. (eds) Handbook of Research on Educational Communications and Technology. Springer, New York, NY.

Dede, C. (2005, January/February). Why design-based research is both important and difficult. Educational Technology, 45 (1). pp. 5-8. 